\title{
Using Parallel Computer Systems to Examine Seismic Reliability of Structures
}

\section{Gu J*}

Thompson Rivers University, Kamloops BC, Canada

\begin{abstract}
Structural response under seismic loadings is typically nonlinear and related to many factors, such as structural configurations, material properties, occupancy loads, earthquake hazards and incomplete knowledge of the system. As all these factors have their sources of uncertainties, structural response under seismic loading has its probabilistic nature. Therefore, the random variable for any structural demand follows a multivariate probability distribution over the integration domain defined by the limit states. Examining the probabilistic behaviour of structures under earthquake loadings has to consider the sources of uncertainties from all factors. It is also known that numerical methods, such as the finite element method, are commonly used to predict nonlinear structural response. The probabilistic structural demand is a discrete probability function of its related variables. In order to examine seismic risks and mitigate potential damages to structures, it is important to accurately quantify seismic reliability of structures. The traditional seismic reliability analysis uses approximate algebra equations with parameters obtained from aggregation of data points of dynamic analysis, which may not be able to produce accurate results. In this paper, probabilistic seismic demands are solved with numerical procedures of the traditional SAC method and the Monte Carlo simulation. These methods rely on the results from repeatable nonlinear dynamic analyses, which were traditionally considered to be a bottle-neck due to limited computing resources. The recent progress in parallel computing technology and open-source software has made such scientific computation affordable for the engineering community. Two parallel computer systems were used to analyze seismic reliability of the structures. One system is based on multiple personal computers in typical computer labs. The other system is to use high performance computer clusters. Both systems were applied to analyze a two-storey wood frame building and a three-storey steel moment building, respectively.
\end{abstract}

Keywords: Seismic reliability; Earthquake engineering; Steel moment resisting frames; Parallel computing; High performance clusters; Monte Carlo simulation; Probability analysis

\section{Introduction}

Structural dynamic response under seismic loading are nonlinear functions of many factors, such as structural configurations, material properties, occupancy loads, earthquake hazards and incomplete knowledge of the system. Thus, structural dynamic response is typically predicted using nonlinear numerical methods, such as the finite element method. The random variable for any structural demand follows a multivariate probability distribution for all related factors over the integration domain defined by the limit states. Due to the nature of numerical analysis of structures with nonlinear behaviour, a closedform solution of the probability distribution may not be available.

A quantitative assessment of the implied reliability level of the designed structures under earthquake loads is needed to address the concerns at targeted performance levels within the life time of the structures. In the past decades, much research work have been conducted to examine risk-based procedures toward performance based earthquake engineering and design. The fragility analysis determines the exceeding probability of demand conditioned on a specific level of intensity measure [1-6]. A fragility analysis does not identify any specific limit state taking into consideration the coupling effect of all random variables. A seismic fragility analysis is commonly used to examine the uncertainty of ground motion records at targeted intensity levels. The fragility analysis is a reasonably accurate method provided that: 1) the source of uncertainties is dominated by earthquake loads; and 2) no uncertainty is associated with targeted intensity measures. The occurrence probability of earthquake intensity measure (IM) is determined by seismologists on a regional basis. Determined hazard levels, such as those specified in the building codes (i.e., the design intensity at $2 \%$ in 50 years) are commonly used by engineers. With the determined intensity targets, the fragility analysis provides reasonable information about the probabilistic behaviour of structures.

The conditional probability distribution described by the fragility analysis can be integrated with the uncertainty of intensity measure in order to determine the coupling effect between ground motions and intensity measure [1,7]. If other random variables are considered, multiple integrals can be applied to conditional distributions of these random variables. This method can incorporate all sources of uncertainties into structural probability analysis and thus has been widely used in analyzing seismic reliability of structures. It can be used to develop a simplified design format similar to the conventional load and resistance factor design $[7,8]$. This method was implemented in the response surface method [9]. It can also be used to determine the probability of failure of components or systems [10,11] and existing buildings [12]. This method can also be implemented into design optimization to study the relationship between seismic risk and potential damage/repair cost [13]. This method is referred to as the traditional method in the following discussion.

In both the fragility analysis and the traditional method, Monte

*Corresponding author: Gu J, Lecturer, Thompson Rivers University, Kamloops BC, Canada, Tel: 1-250-828-5048; E-mail: jgu@tru.ca

Received September 19, 2015; Accepted October 01, 2015; Published October 07, 2015

Citation: Gu J (2015) Using Parallel Computer Systems to Examine Seismic Reliability of Structures. J Steel Struct Constr 1: 101. doi:10.4172/24720437.1000101

Copyright: (c) $2015 \mathrm{Gu}$ J. This is an open-access article distributed under the terms of the Creative Commons Attribution License, which permits unrestricted use, distribution, and reproduction in any medium, provided the original author and source are credited. 
Carlo simulation (MCS) is commonly used to sample variables other than those from earthquakes [12-19]. With the samples from MCS, the traditional method uses data fitting techniques to obtain parameters from the results of simulation, which may not be able to produce accurate results. In order to accurately quantify and examine the probabilistic seismic behaviour, two numerical methods were used here to produce cumulative probability distributions of structural demands. One method is the numerical format of the traditional method. Compared with the traditional method using aggregated parameters from data-fitting techniques, the numerical procedure is accurate, especially when the coupling effect from different sources of uncertainties is interested. The other method is the MCS that applies to all sources of uncertainties, including the intensity measure. The background and rational of this method can be found fund in a previous study [20]. Both methods have been employed in analyzing seismic reliability analysis of structures.

Using numerical procedures to examine seismic reliability of structures requires a significant number of nonlinear time history analysis (NTHA), which was considered to be a bottle-neck using traditional personal computers. It is noted that NTHA for seismic reliability analysis has its parallel characteristics and can be executed by multiple computers connected in parallel. Two parallel computer systems are reported here to discuss their applications. One system is based on multiple PCs in typical university computer labs. This system was used to analyze the probabilistic seismic behaviour of a two-storey wood frame building. The other system is to use a specialized software running on high performance computer clusters. A three-storey steel moment frame building was analyzed using this system to study its seismic reliability. The results of both systems were reported and discussed, and some recommendations were made.

\section{Methodologies}

\section{Reliability methods}

The traditional method: Two seismic reliability methods were used to examine the application of parallel computational systems. The first method is the traditional method, which estimates the exceeding probability of drift demand from conditional distributions given intensity levels [7], shown as:

$$
F_{D}(d)=P(D \leq d) \approx \int_{0}^{+\infty} P[D(a) \leq d \mid I M=x] f_{I M}(x) d x
$$

Where $P[D(a) \leq d \mid I M=x]$ is the conditional cumulative distribution function (CDF) of drift demand, $\mathrm{D}$, not exceeding the value $\mathrm{d}$, given the intensity level of $I M=x$. This conditional distribution of drift demand, $\mathrm{D}$, has the uncertainties from ground motion records, $\mathrm{r}$, and resistance properties, a.

The exceeding probability, $P[D(a) \leq d \mid I M=x]$, may be obtained by rank-ordering the results of nonlinear time-history analysis with multiple combinations of inputs. The combinations of input are vector samples [21] from resistance properties and ground motion records scaled to the targeted intensity level of $I M=x$. Then, NTHA is performed to generate the demand. The results of the demand are rankordered to produce the conditional distribution of $P[D(a) \leq y \mid M=x]$. If sufficient samples are used in the analysis, the result of the conditional probability distribution from this calculation can be very accurate. Alternatively, this distribution may be obtained from the chain rule of the probability theory for all its random variables.

With the probability density function of capacity, $f_{C}(y)$, the probability of failure may be expressed as:

$$
\begin{aligned}
& P_{f}=\int_{0}^{+\infty} f_{C}(y)\left[1-F_{D}(y)\right] d y \\
& \approx \int_{0}^{+\infty} f_{C}(y)\left\{1-\int_{0}^{+\infty} P[D(a) \leq y \mid I M=x] f_{I M}(x) d x\right\} d y
\end{aligned}
$$

Considering the nature of NTHA, a closed-form solution to Eq. (3) may not exist. With certain assumptions for the random variables, this method was used to obtain an algebra equation with its coefficients data-fitted from limited NTHA [1]. In order to obtain an accurate result from this method, Eq. (3) can be rewritten using the discrete method, shown as:

$$
P_{f}=\sum_{k=0}^{L} f_{C}\left(y_{k}\right)\left\{1-\sum_{i=0}^{M} P\left[D(a) \leq y \mid I M=x_{i}\right] f_{I M}\left(x_{i}\right) \Delta x_{i}\right\} \Delta y_{k}
$$

Where $\mathrm{M}$ is the number of intensity levels and $\mathrm{L}$ is the number of capacity levels. The discrete samples of seismic weight have been incorporated in the conditional CDF.

In this study, the conditional probability distributions, $P[D(a) \leq y \mid I M=x]$, with uncertainties from ground motion records and seismic weights were used to compare the influence of different factors. This calculation produces multiple probability distribution curves at different levels of intensity at $I M=x$.

The numerical procedure illustrated in Eq. (4) was originally developed to study seismic reliability of wood frame structures [20]. This procedure is more accurate than the original work [7], in which Eq. (3) was used to obtain some simplified algebra equations with parameters obtained from data-fitting techniques. However, this procedure requires significant amount of NTHA, which is considered to be time-consuming and thus needs parallel computing technology.

The Monte Carlo simulation: The probability distribution of ground motion records can be viewed as a uniform distribution. Each record is a natural sample representing the ground motion characteristics. Considering that the distribution of intensity and seismic weights can be defined with statistical data, the drift demand follows a joint multivariate distribution of resistance, records and intensity. If other uncertainty sources are considered, the joint distribution will have more random variables. The MCS may be used as a benchmark to account for the uncertainties from different sources.

This method is an extension of the traditional MCS to engage the uncertainty from ground motion records, based on the discrete nature of ground motions. If there are an infinite number of ground motion records, the ground motion characteristics can be sampled as a regular random variable and thus be combined with other variables as illustrated by MCS. Since the ground motions available for a particular analysis are always limited, a special sampling technique is needed. It is noted that the occurrence probability of each record is $1 / \mathrm{N}$, where $\mathrm{N}$ is the total number of records. Then, all random variables are divided into two groups, one for ground motions and the other for the rest of variables. The other group is regularly sampled with the number of combinations denoted as T. All T combinations are mixed with $\mathrm{N}$ ground motions to generate $T \times N$ grid samples, each of which is a set of input for NTHA. The results of the demand measure from the $T \times N$ NTHA forms data points for the CDF [20].

It is well-known that iterations are typically required for nonlinear problems. As the input for NTHA generated by pseudo-random numbers typically requires a significant number of iterations, the 
computational efficiency may be compromised. On the other hand, the MCS can be viewed as a numerical integration in its domain. Therefore, grid based samples or sequence samples can be used in numerical integration to obtain results of the MCS. The computational efficiency using grid based samples or sequence samples are predictable compared with pseudo-random samples, which makes the MCS relatively efficient. This type of MCS is commonly cited as the quasiMonte Carlo simulation [22].

\section{A computational procedure with multiple PCs}

Using the discrete format of the traditional method or the MCS requires repeatable NTHA. These repeatable calculations are for the same system with different vector inputs to consider their uncertainties. On one hand, the process of each calculation itself is performed step by step in the time domain. In each time step, the iteration to achieve the convergence involves some algorithms, such as the Newton-Raphson method. All of these iteration steps are to be performed in a serial manner, the order of which cannot be alternated easily. Therefore, each NTHA is in a sequence-based calculation, which efficiency is primarily dominated by the processor's speed. The parallel computing technology cannot be directly applied to speed up the computational process of any individual NTHA, except some systems have a large amount of elements or degree-of-freedoms. On the other hand, all NTHA are independent from each other, all of which do not need any communication with other NTHA during the execution. Since only the final results are needed for probabilistic analysis, the demand for information communication during the calculation is minimum. Therefore, these NTHA can be viewed as parallel and can be executed by different processors on any parallel computing system, regardless whether the computer processors are located locally or remotely.

This computational procedure aims to utilize the resource of multiple personal computers (PCs) that are commonly available in university computer labs. These PCs are typically idle in the evenings, weekends and non-instructional seasons. NTHA for the discussed probabilistic analysis can be performed on these PCs without any capital investment.

Several attempts were made to utilize the computer resources in the labs. The procedure shown in Figure 1 was developed for NTHA programs using traditional computational languages, such as Fortran 77/90 and C. Examples of these programs include CASHEW [23] and DRAIN-2DX [24], which are typically programed with modules for simplicity. But these programs are not object-oriented and are difficult to be controlled via the network. Therefore, these numerical programs are compiled separately as executable files, so that they can be executed remotely when needed. These executable programs are stored on

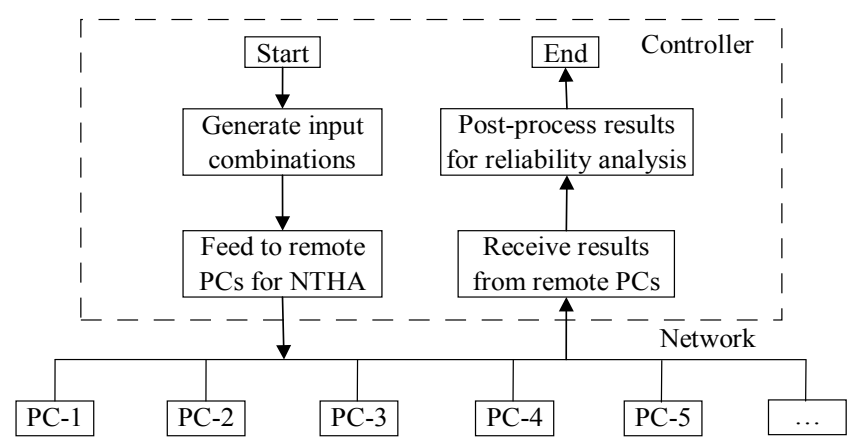

Figure 1: Flowchart for a Lab-based. multiple processors, as indicted by "PC-1", "PC-2" and so on, in Figure 1.

In order to feed input to and extract output from the processors, a control program, as shown in Figure 1 needs to be developed. The main function of this control program is to pre-process the input and postprocess the output as required for the reliability analysis. In the preprocess stage, this program generates the combinations of inputs from all random variables for the reliability methods as discussed above. Then these inputs are sent to the processors through the network for NTHA. After NTHA is finished, the results are sent back to this control program to generate probability distribution functions and visualize results. This control program was written in Microsoft Excel with Visual Basic Script and run on "PC-0" as shown in Figure 1.

In order to send the input to remote processors, check their executable status and retrieve the results back to the control program, an interface communicating through the network is needed. At the beginning, both Telnet and Microsoft PowerShell were tried on a small network with some success. However, they were not permitted to run on a university network, because of concerns on the network security. Finally, Ultra VNC [25] was used in the analysis. UltraVNC is a remote control program, which enables users to check the running status on remote processors and manually send files to the controller.

\section{Procedure}

\section{OpenSees on high performance clusters}

OpenSees is an object-oriented open-source software framework for developing nonlinear finite element applications [26]. Opensees has the capability to run in parallel as well as serial environments. The parallel version of OpenSees streamlines the communication process among multiple processors in a convenient way. It permits users to directly specify and allocate processors in the control program. One of the advantages to use OpenSees on high performance clusters (HPCs) is the simplification of communication via the network, so that engineers can focus on structural modeling. The mechanism of OpenSees is similar to Figure 1. The HPCs of Westgrid, a part of Compute Canada, were used as the computational platform to run OpenSees.

\section{Random variables}

Three sources of uncertainties were considered in the analysis: seismic weights, record-to-record uncertainty, and intensity measure. Seismic weights mainly come from dead loads of structural and nonstructural components. A lognormal distribution with a coefficient of variation (COV) of 0.1 was assumed for seismic weights of all floors and roofs. Generally, the seismic weights at different floors and roof can be assumed to be uncorrelated or having a correlation coefficient not significantly different from zero. However, uncorrelated seismic weights may produce some cases with significant vertical weight irregularities which are either not permitted by typical building codes or should be avoided by construction practice. It was also noted that the floor assembly is commonly the same for all levels. The materials for all levels were assumed to come from the same suppliers or perhaps even the same shipment. Thus, it would be reasonable to assume that seismic weights at different floor levels are highly correlated. It would be practical and reasonable for this paper to assume that the correlation coefficients between any two floors are equal to 1 .

A suite of 22 pairs of ordinary earthquake ground motion records by FEMA P-695 [27] were used as the input for the nonlinear timehistory analysis. These ground motion records were scaled to multiple levels of intensity measure using a scaling method to account for the 
variation of earthquake loads. The scaling process involved three steps: i) the normalization, ii) the basic scaling and iii) the secondary scaling. The first two steps were used by FEMA P-695. During the normalization, all records were scaled to their median peak ground velocity. In the second step, all records were scaled to have a median spectral acceleration $\left(S_{2}\right)$ to match the targeted spectral acceleration for the maximum considered earthquake (MCE) at the fundamental period. With the second step, the ground motion records were scaled to a deterministic level of intensity (i.e., the median spectral acceleration). To ensure a probabilistic analysis, the targeted intensity level should not be deterministic. The third step, secondary scaling, was used to consider the uncertainty of intensity measure for reliability analysis with the scaling factors dependent on the selected distribution types as discussed below.

The annual occurrence probability of intensity measure, $H(\cdot)$, is traditionally assumed to be linear on a log-log plot [7], shown as:

$$
H\left(S_{a}\right)=a S_{a}^{-b}
$$

where $S_{a}=$ spectral acceleration; $a$ and $b$ are parameters. This assumption produces an extreme-type distribution for the targeted exceeding probability within the expected life time of the structures. In addition, a lognormal distribution was also used to examine the consequence from reasonably large earthquakes within the life time of structures. The parameters $a$ and $b$ in Eq. (5) were chosen to be 0.0144 and 3.2, respectively. With these parameters, the scaling factor for the second scaling is defined as the ratio of a sample of the distribution to the median spectral acceleration for the Seismic Design Category (SDC) of $\mathrm{D}_{\text {max }}$ as defined in FEMA P-695.

Different combinations of sample numbers were used to investigate their influences. After several trials, it was found those 40 samples for intensity and 16 samples for seismic weights, following the technique for quasi-Monte Carlo simulation. With 22 samples of ground motion records (i.e., 22 pairs of records), the preliminary calculation ran NTHA for 14080 times.

\section{Examples}

\section{A two-storey wood frame building}

The building is a two-storey wood frame house tested as a part of the CUREE-Caltech Wood frame project at UCSD [28]. This building has a footprint of $4.9 \mathrm{~m} \times 6.1 \mathrm{~m}$ and a storey height of $2.6 \mathrm{~m}$. The clear storey height is $2464 \mathrm{~mm}$. Figure 2 shows the floor plans of this building. The lateral force resistance system of the building relied on

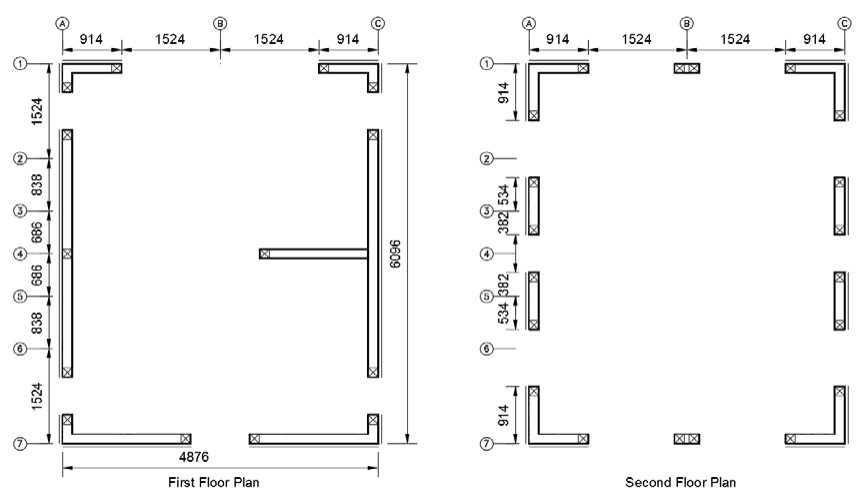

Figure 2: Floor plans of the wood frame building.
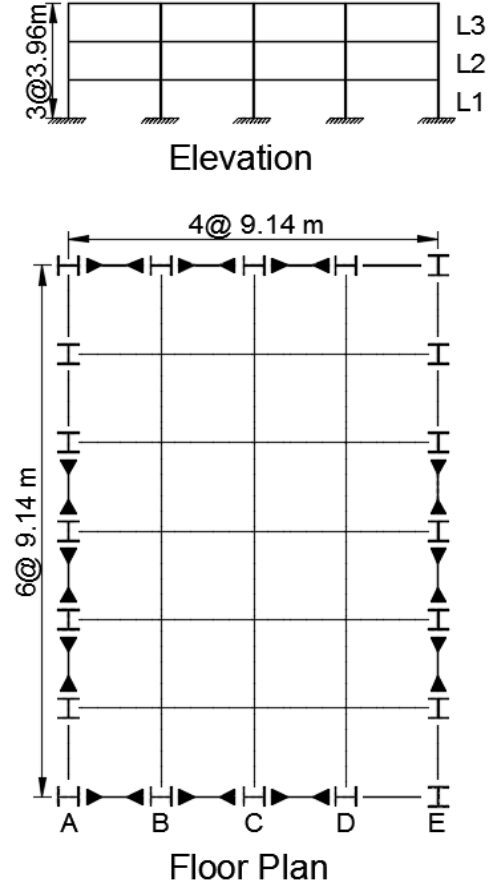

Figure 3: Elevation and floor plan the steel moment frame building.

exterior walls. The walls along the short direction (i.e., the north-south direction) had large openings for doors and windows and thus were considered to be the weak direction. All exterior walls were sheathed with $9.5-\mathrm{mm}$ thick oriented strand board (OSB) panels that fastened to the framing with 8-penny box gun nails. Tie-downs and steel straps were used at all openings. 12-mm thick gypsum wallboard (GWB) panels were installed on the interior side with $32-\mathrm{mm}$ long screws. A total thickness of $22 \mathrm{~mm}$ of stucco with 17-gauge galvanized steel wire lath was applied to the exterior connected with $20-\mathrm{mm}$ long staples. Further details of this building can be found for the Phase 10 test in related publications $[28,29]$.

\section{A three-storey steel moment frame building}

This steel moment resisting frame (SMRF) building developed as a part of the SAC steel project [30] was investigated for its probabilistic behaviour under earthquake loadings. The examined building had three storeys and was designed following the code requirements for Los Angles by using the post-Northridge design [31]. This building did not have a basement. The failure modes of buildings following the postNorthridge design buildings are considered to be very ductile and may be well-represented by drift used in this study [31]. The building has a grid spacing of $9.14 \mathrm{~m}$ and a typical storey height of $3.96 \mathrm{~m}$. The SMRF systems locate along the perimeter of the building. The design yield strength for the beams, girders and columns is $345 \mathrm{MPa}$ (50 ksi). Other information about the buildings is presented in FEMA 355C. The plan and elevation of this building is shown in Figure 3. The details for reduced-beam-section connections are discussed in FEMA 355D, with some information referred to the background document [32]. Spectral acceleration was used as the intensity measure, as mentioned above.

\section{Results}

Results of the wood frame building 
Nonlinear dynamic analysis was performed using the numerical programs SAWS (seismic analysis of woodframe structures) and CASHEW (cyclic analysis of shear walls), two programs that were developed by the CUREE-Caltech Woodframe project $[5,10]$. The SAWS program is a pancake model using the assumptions of rigid diaphragms and zero-height nonlinear springs. Incremental dynamic analysis (IDA) [33] was performed at different levels of intensity. The SAWS program was incorporated into a Microsoft Excel spreadsheet using Visual Basic for iterative calculation and data visualization and can be controlled remotely.

The calculation of this building was performed in a computer lab with 30 computers following the procedure shown in Figure 1. These computers were Dell Optiplex 380 equipped with Intel Pentium E850 DuoCore processors. With the results from the calculation, reliability analysis of this building can be performed. Figure 4 shows the conditional distribution curves at given intensity levels, as indicated in Eq. (1). Each curve is a conditional cumulative probability function (CDF) at one intensity level. Since 40 levels of intensity levels were used in the analysis, there are $40 \mathrm{CDF}$ curves in total. The curves on the left side are typically at low levels of intensity, while ones on the right side are at high levels of intensity. With these conditional CDF, the probability of failure at a drift capacity of 3\% can be calculated. The results are shown in Table 1 . The drift demand corresponding to the probability of failure of $10 \%$ is also shown. Figure 5 presents the results of the MCS, from which the probability of failure at $3 \%$ is also shown in Table 1 .

\section{Results of the steel frame building}

The steel moment frame building was modeled as a "M2" model (FEMA 355C) with zero-length rotational springs to represent plastic hinges and elements with rigid boundaries to represent panel zones. Other beams and columns were modeled with rigid elements. The rotational springs used the Ibarra-Krawinkler deterioration model [34-36]. 3\% strain hardening was used in the analysis of hinges. The viscous damping was chosen to be $2 \%$ for the first mode and the mode at a period of $0.2 \mathrm{~s}$. The geometrical nonlinearity of the building is simulated with a bay of P-delta leaning columns. The open-source software, OpenSees [26], was used to establish the model of the steel

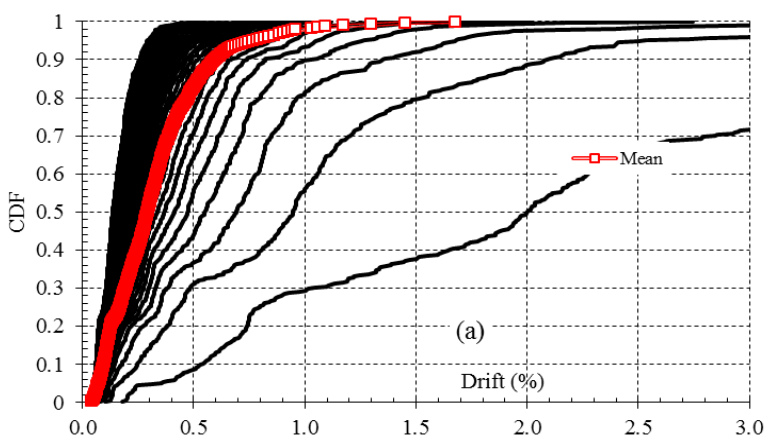

Figure 4: Conditional distributions at given intensity for the wood frame building.

\begin{tabular}{|l|c|c|}
\hline & $\mathrm{P}_{\mathrm{f}} @ 3 \%$ drift & Drift @ $\mathrm{P}_{\mathrm{f}}=10 \%$ \\
\hline Traditional method & $0.85 \%$ & $0.60 \%$ \\
\hline MCS & $0.90 \%$ & $0.63 \%$ \\
\hline
\end{tabular}

Table 1: Exceeding probability at $3 \%$ drift capacity and drift capacity at $10 \%$ exceeding probability for the wood frame building.

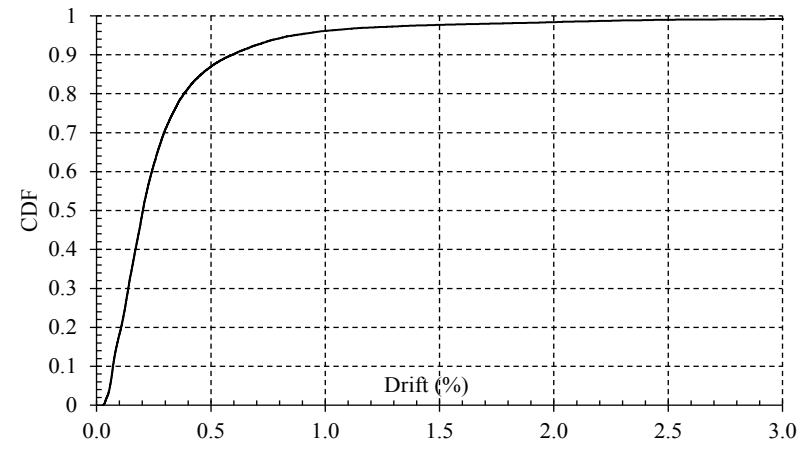

Figure 5: CDF from the monte carlo simulation for the wood frame building.

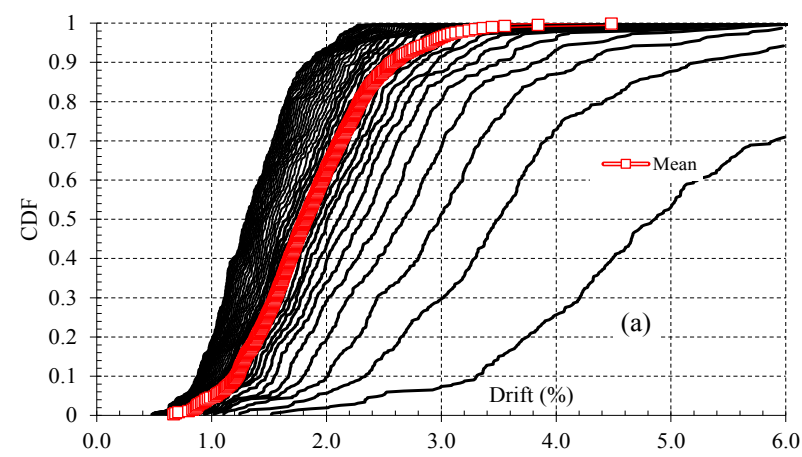

Figure 6: Conditional distributions at given intensity for the steel building

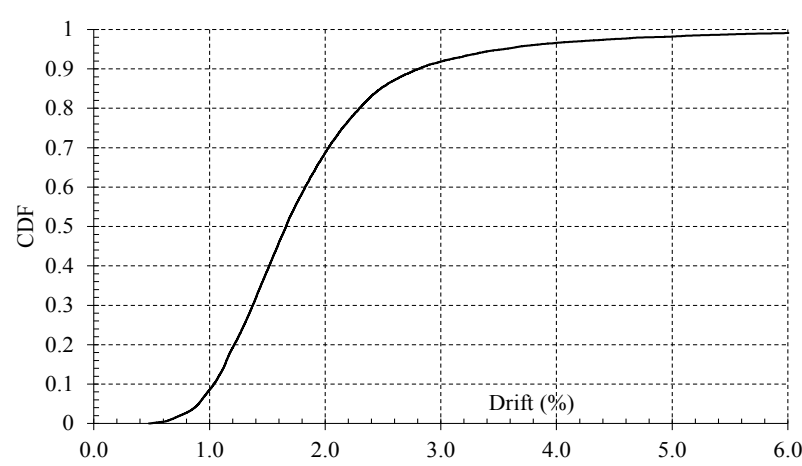

Figure 7: CDF from the monte carlo simulation for the steel building.

moment frame building. It was found that the model was not efficient to run the lab computers as indicated in Figure 1. The major challenge was the problem of convergency at large scale factors for some ground motions. Finally, a parallel verion of OpenSees was installed on three high performance clusters of Westgrid, including Nestor, Grex and Bubagoo. The parallel version of the OpenSees streamlines the operation of mutiple processors in a simple way, which enables engineers to focus on structural modeling, rather than the technical details of the network. Nonlinear dynamic analysis with this building model was finally executed on these clusters smoothly and successfully.

The drift demand was processed to produce the conditional CDF for the traditional method, with the results shown in Figure 6. The 


\begin{tabular}{|l|c|c|}
\hline & $\mathrm{P}_{\mathrm{f}} @ 3 \%$ drift & Drift @ $\mathrm{P}_{\mathrm{f}}=10 \%$ \\
\hline Traditional method & $8.18 \%$ & $2.81 \%$ \\
\hline MCS & $8.86 \%$ & $2.83 \%$ \\
\hline
\end{tabular}

Table 2: Exceeding probability at $3 \%$ drift capacity and drift capacity at $10 \%$ exceeding probability for the steel building.

probability distribution of drift demand calculated from the MCS is shown in Figure 7. With these CDF, the probability of failure can be determined, as shown in Table 2.

\section{Discussions and Conclusions}

Two types of parallel computing systems were used in analyzing seismic reliability of a wood frame building and a steel moment frame building. One system was developed for multiple PCs in typical university computer labs. Reliability analysis of a two-storey wood frame building was analyzed with this system. The results of the building proved that this system is feasible in utilizing the computing resources for this wood frame building. It was also found that the operation through the network with this system needs to be streamlined for parallel computation. This may be improved by some specially designed software for parallel computation, such as the open grid system. The other system is to use the special software, OpenSees, on high performance computer clusters. A three-storey steel moment frame building was analyzed using this system to study its seismic reliability. The advantage of this system is the capability of parallel computing without direct technical operation with the network, which saves much time for researchers.

\section{Acknowledgements}

The author thanks Westgrid and its site managers for the computational resource and technical support to use the clusters.

\section{References}

1. Ellingwood BR (2001) Earthquake risk assessment of building structures Reliability Engineering and System Safety 74: 251-262.

2. Rosowsky DV, Ellingwood BR (2002) Performance-based engineering of wood frame housing: Fragility analysis methodology. Journal of Structural Engineering 128: 32-38.

3. Wen YK, Ellingwood BR (2005) The role of fragility assessment in consequencebased engineering. Earthquake Spectra 21: 861-877

4. Kazantzi AK, Righiniotis TD, Chryssanthopoulos MK (2008) Fragility and hazard analysis of a welded steel Moment Resisting Frame. Journal of Earthquake Engineering 12: 596-615.

5. Pang W, Rosowsky DV, Ellingwood BR, Wang Y (2009) Seismic fragility analysis and retrofit of conventional residential wood-frame structures in the Central United States. Journal of Structural Engineering ASCE 135: 262-271.

6. Li Y, Song R, Van de Lindt J (2014) Collapse fragility of steel structures subjected to earthquake mainshock-aftershock sequences. Journal of Structural Engineering ASCE 140: 04014095.

7. Cornell CA, Fatemeh J, Hamburger RO, Foutch DA (2002) Probabilistic basis for 2000 SAC Federal Emergency Management Agency steel moment frame guidelines. Journal of Structural Engineering ASCE 128: 526-533.

8. Yun SY, Hamburger RO, Cornell CA, Foutch DA (2002) Seismic performance evaluation for steel moment frames. Journal of Structural Engineering ASCE 128: 534-545.

9. Zhang J, Foschi RO (2004) Performance-based design and seismic reliability analysis using designed experiments and neural networks. Probabilistic Engineering and Mechanics 19: 259-267.

10. Celik OC, Ellingwood BR (2010) Seismic fragilities for non-ductile reinforced concrete frames - Role of aleatoric and epistemic uncertainties. Structural Safety 32: 1-12.

11. Liao KW, Wen YK, Foutch DA (2007) Evaluation of 3D steel moment frames under earthquake excitations. II: Reliability and redundancy. Journal of Structural Engineering 133: 471-480.
12. Li Q, Ellingwood BR (2008) Damage inspection and vulnerability analysis of existing buildings with steel moment-resisting frames. Engineering Structures 30: $338-351$

13. Yang TY, Moehle J, Stojadinovic B, Der Kiureghian A (2009) Seismic performance evaluation of facilities: methodology and implementation. Journal of Structural Engineering 135: 1146-1154.

14. Au SK, Beck JL (2003) Subset simulation and its application to seismic risk based on dynamic analysis. Journal of Engineering Mechanics 129: 901-917.

15. Lupoi G, Franchin P, Lupoi A, Pinto PE (2006) Seismic fragility analysis of structural systems. Journal of Engineering Mechanics 132: 385-395

16. Liel AB, Haselton CB, Deierlein GG, Baker, JW (2009). Incorporating modeling uncertainties in the assessment of seismic collapse risk of buildings. Structura Safety 31: 197-211.

17. Tubaldi E, Barbato M, Dall'Asta A (2012) Parameter uncertainty on seismic transverse response and vulnerability of steel-concrete composite bridges with dual load path. Journal of Structural Engineering 138: 363-374.

18. Decò A, Bocchini P, Frangopol DM (2013) A probabilistic approach fo the prediction of seismic resilience of bridges. Earthquake Engineering and Structural Dynamics Volume 42: 1469-1487.

19. Vamvatsikos D (2014) Seismic performance uncertainty estimation via IDA with progressive accelerogram-wise Latin Hypercube sampling. Journal of Structural Engineering.

20. Gu J (2014) Seismic Reliability Analysis of Wood Shear Walls Using Different Methods. Journal of Structural Engineering.

21. Baker JW (2007) Probabilistic Structural Response Assessment Using VectorValued Intensity Measures. Earthquake Engineering and Structural Dynamics 36: 1861-1883.

22. Niederreiter H (1978) Quasi-Monte Carlo Method and Pseudo-random Numbers. Bulletin of the American Mathematical Society 84: 957-1041.

23. Folz B, Filiatrault A (2001) Cyclic Analysis of Wood Shear Walls. Journal of Structural Engineering 127: 433-441.

24. Prakash V, Powell G, Campbell S (1993) DRAIN-2DX [Computer software] University of California, Berkeley, California, USA.

25. UltraVNC Team (2013) UltraVNC X64 Server and Viewer.

26. Pacific Earthquake Engineering Research Center (2014) Open System for Earthquake Engineering Simulation - OpenSees. Version 2.4.4, Berkeley, California, USA.

27. Applied Technology Council (2009) Quantification of building seismic performance factors. FEMA P-695, Federal Emergency Management Agency (FEMA), U.S. Department of Homeland Security, Washington, DC, USA.

28. Fischer D, Filiatrault A, Folz B, Uang CM, Seible F (2001) Shake table tests of a two-story woodframe house. Consortium of Universities for Research in Earthquake Engineering, Richmond, California, USA

29. Folz B, Faliatrault A (2004) Seismic Analysis of Woodframe Structures. Journal of Structural Engineering 130: 1353-1360.

30. FEMA (2000) State of the art report on systems performance of steel moment frames subjected to earthquake ground shaking. Washington, DC, USA

31. FEMA (2000) State of the art report on connection performance. Washington, DC, USA.

32. Krawinkler H, Gupta A (2000) Benchmarking of analysis programs for SMRF system performance studies. Stanford University, California, USA.

33. Vamvatsikos D, Cornell CA (2002) Incremental dynamic analysis. Earthquake Engineering and Structural Dynamics 31: 491-514.

34. Ibarra LF, Krawinkler $\mathrm{H}$ (2005) Global collapse of frame structures under seismic excitations. The John A. Blume Earthquake Engineering Research Center, Department of Civil Engineering, Stanford University, Stanford, CA, USA.

35. Zareian F, Medina RA (2010) A practical method for proper modeling of structural damping in inelastic plane structural systems. Computers and Structures 88: 45-53.

36. Lignos D, Krawinkler H (2011) Deterioration Modeling of Steel Components in Support of Collapse Prediction of Steel Moment Frames under Earthquake Loading. Journal of Structural Engineering 137: 1291-1302. 